\title{
OPEN Chemical characterization of Saudi propolis and its antiparasitic and anticancer properties
}

\author{
Samyah Alanazi ${ }^{1}$, Naif Alenzi ${ }^{2 凶}$, Fouza Alenazi ${ }^{2}$, Hajera Tabassum ${ }^{1} \&$ David Watson $^{3}$
}

Propolis, is a gummy material produced by honey bees from different parts of plants and is enriched with varied biological active compounds like flavonoids, phenolics and phenolic acids with wide applicability in the food, pharmaceutical and cosmetics industries. The current report is focused on the characterisation of propolis collected from Asir region, South-west of Saudi Arabia and its effect on Trypanosoma brucei (the causative organism of African sleeping sickness) and cytotoxic effect against U937 human leukemia cells. The Chemical composition and spectral characteristics of Saudi propolis was studied by Liquid Chromatography Mass Spectrometry (LC-MS) and High-performance liquid chromatography-evaporative light scattering detector (HPLC-ELSD).The two main active compounds isolated from Saudi propolis via column chromatography and size exclusion chromatography were fisetinidol and ferulic acid. High resolution electrospray ionization-mass spectrophotometer (HRESI-MS) and nuclear magnetic resonance (NMR) were used to elucidate the structures of the isolated compounds. All crudes extracts, fractions as well as isolated compounds were subjected for biological testing against Trypanosoma brucei (S427 WT), and their cytotoxicity against U937 human leukemia cells. Amongst the various samples investigated, S- 6 fraction demonstrated highest anti-trypanosomal activity at $2.4 \mu \mathrm{g} / \mathrm{ml} \mathrm{MIC} \mathrm{followed} \mathrm{by} \mathrm{fisetinidol} \mathrm{at} 4.7 \mu \mathrm{g} / \mathrm{ml}$ reflecting that the anti-trypanosomal activity is attributable to the presence of fisetinidol in the fraction. Similarly, all the tested samples exhibited cytotoxicity with an IC50>60 $\mu \mathrm{g} / \mathrm{ml}$. S- 6 fractions exhibited highest cytotoxic activity against U937 cells with an IC50 of $58.7 \mu \mathrm{g} / \mathrm{ml}$ followed by ferulic acid with an IC50 $87.7 \mu \mathrm{g} / \mathrm{ml}$ indicating that the cytotoxic effect of propolis might be due to the presence of ferulic acid. In conclusion, the biological activity of propolis could be attributed to the synergistic action of the two active compounds-ferulic acid and fisetinidol. The data obtained in the study is thus indicative of the role of propolis as potential anti-trypanosomal and anticancer agent for effective cancer therapy.

Propolis is a natural gummy, and resinous substance with a complex and diverse composition comprising mainly beeswax and secondary metabolites from plants. Propolis or bee glue is produced by honeybees (Apis mellifera L.) from plant-derived materials during the process of sterilizing the hive environment ${ }^{1}$, thus ensuring the bee community's health. In Saudi Arabia, the mountainous area in the south-west of the country, including Asir, is considered ideal for honey collection ${ }^{2}$ due to the conditions and vegetation (moderate weather during summer in addition to an abundance of trees and flowery shrubs) that are conducive to the bee species of Apis mellifera jemenitica ${ }^{3}$. Phytochemical data on Saudi Arabian propolis is scarce. It is speculated that the propolis production involves partial digestion or mixing with saliva of the materials gathered from plant bark, buds and flowers ${ }^{4}$, however, there is no positive evidence of such chemical changes ${ }^{1}$. Bees colonies that produce substantial quantities of propolis have been reported to be cleaner, achieve greater honey production, have a highly viable brood, and longer living worker bees ${ }^{5}$.

Propolis has been used as a popular traditional medicine since ancient times throughout the world ${ }^{6}$. It is currently used as alternative medicine and in health foods. The chemical composition of propolis varies by geographical location, botanical source, and bee species ${ }^{7}$. Until 2000, over 300 chemical components belonging to the flavonoids, terpenes, and phenols have been identified in propolis. The characteristic constituents of propolis in the temperate region are flavonoids such as chrysin, galangin, pinocembrin, and pinobanksin. Caffeic acid phenethyl ester is a major constituent of temperate propolis with broad biological activities. Brazilian

\footnotetext{
${ }^{1}$ Department of Clinical Laboratory Sciences, College of Applied Medical Sciences, King Saud University, Riyadh, Saudi Arabia. ${ }^{2}$ Research and Laboratories Sector, National Drug and Cosmetic Control Laboratories (NDCCL), Saudi Food and Drug Authority, Riyadh, Saudi Arabia. ${ }^{3}$ Strathclyde Institute of Pharmacy and Biomedical Sciences, University of Strathclyde, Glasgow, UK.『email: Ndenzi@sfda.gov.sa
} 

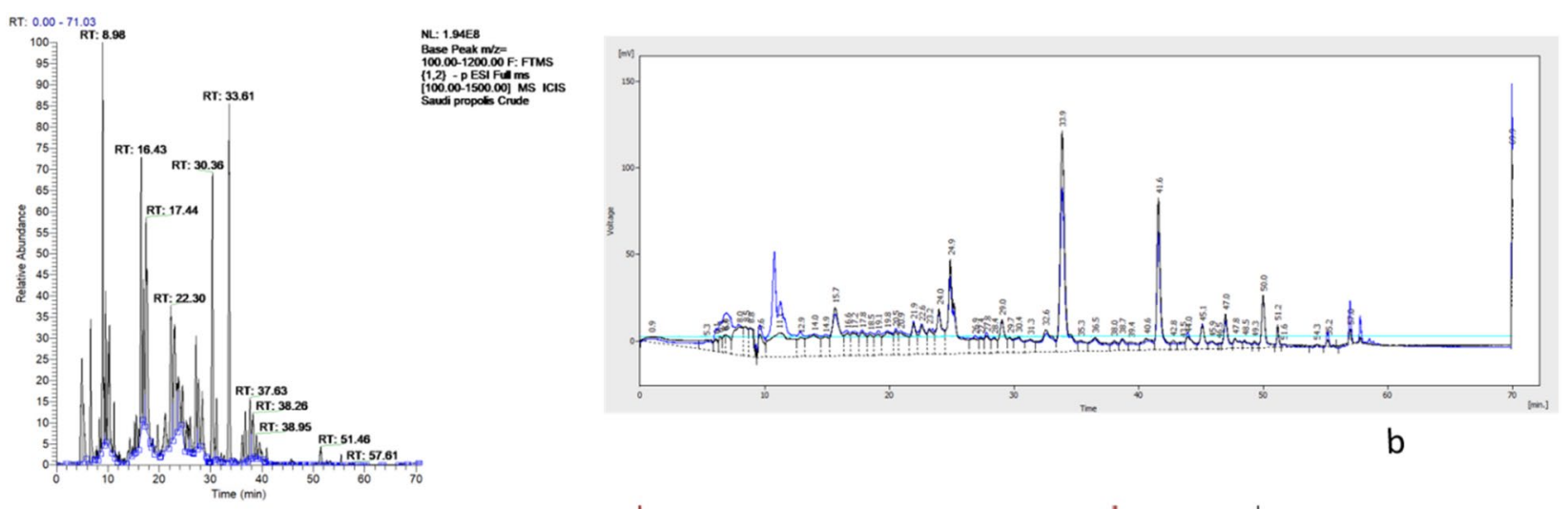

a

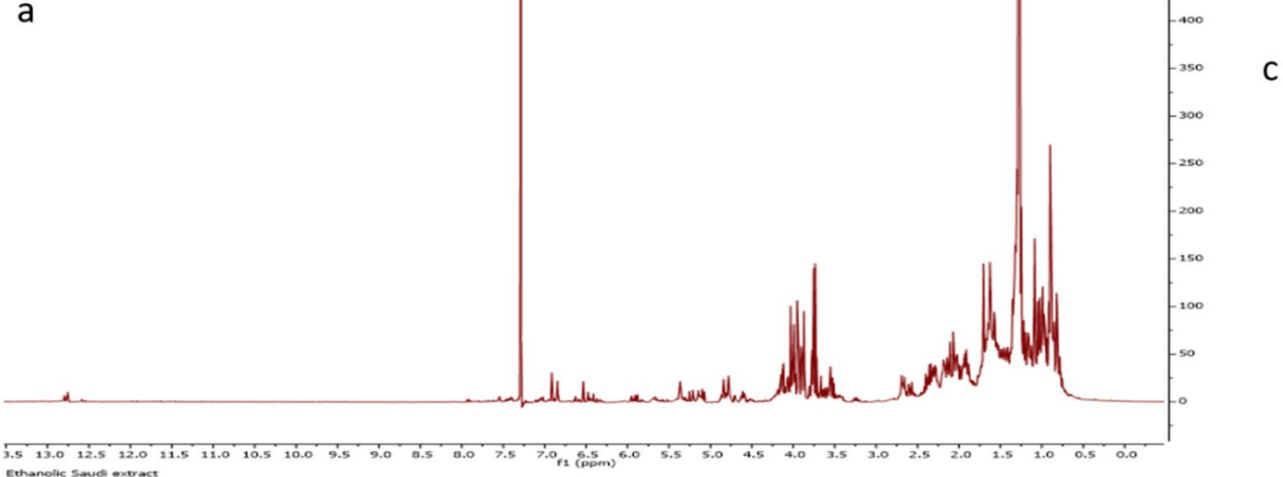

Figure 1. Chemical profile of crude Propolis extract (a) LC-MS Chromatogram of ethanol-based crude extract, (b) HPLC-ELSD profile of ethanolic crude Propolis extract and (c) ${ }^{1} \mathrm{H}$ NMR spectrum of ethanol-based Saudi propolis extract in $\mathrm{CDCl}_{3}$.

green propolis primarily contains prenylated phenylpropanoids and diterpenes. Propolis from the Pacific region contains geranyl flavanones, which are also found in propolis from African regions ${ }^{8}$.

Propolis is extensively employed in preventing and treating colds, wounds, and ulcers, rheumatism, sprains, heart disease, diabetes, and dental caries due to its biological effects against cancer ${ }^{9}$, inflammation, and oxidants ${ }^{10}$, microbes $^{11}$, and cell growth ${ }^{12}$. Based on the age and origin, propolis displays different colors yellow, dark brown, or even transparent ${ }^{13}$. At temperatures in the range of $25-45^{\circ} \mathrm{C}$, propolis typically begins to soften, becomes malleable, and highly sticky. Conversely, at temperatures below $15^{\circ} \mathrm{C}$, propolis becomes hard and brittle, and after it is frozen, it maintains its brittleness even at high temperatures. The usual melting point for propolis is $60-70^{\circ} \mathrm{C}$, although it may be up to $100^{\circ} \mathrm{C}$ for some samples. Ethanol, ether, glycerol, and water are the main solvents employed for extracting propolis for commercial purposes; other solvents are also available ${ }^{14}$. Ethanol is mostly used to obtain low wax propolis extracts rich in biologically active compounds. The chemical composition of propolis has attracted interest due to its broad use in modern herbal medicine. Studies from different countries have shown the antimicrobial ${ }^{15,16}$, anti-inflammatory ${ }^{17}$, cytotoxic $^{18,19}$, antiparasitic properties ${ }^{20}$, immunomodulatory ${ }^{21,22}$, and anti-leishmanicidal effects of different propolis extracts from different sources ${ }^{23,24}$. However, data on the anticancer and anti-trypanosomal activity of Saudi propolis is scarce. In view of the above, the present study was undertaken to chemically characterize the compounds in Saudi propolis and evaluate its anti-trypanosomal and anticancer properties.

\section{Results}

Profiling of crude Saudi propolis with LC and HPLC-UV-ELSD. Crude propolis extract characterized using liquid chromatography-mass spectrometry (LC-MS) is shown in Fig. 1a. The LC-MS results detail most constituents and the nature of the constituents in the crude ethanolic extract. LC-MS profiling demonstrated the occurrence of flavonoids and other phenolics in the ethanol-based crude extract of propolis. The chromatograms of the crude samples run on HPLC-UV-ELSD (Fig. 1b) show a wide diversity in the chemical composition of propolis samples from Saudi Arabia.

The HPLC-UV-ELSD profile of the crude sample confirmed the occurrence of compounds absorbing ultraviolet (UV) light, such as flavonoids and phenolic compounds. Compounds lacking chromophores, including some terpenoids, were also identified; their intensities were low. Considerable complexity was exhibited by the LC-MS chromatogram of the crude sample, revealing multiple peaks of varying intensities. The flavonoids and phenolics were also confirmed as the dominant constituents by the ${ }^{1} \mathrm{H}$ NMR spectra (Fig. $3 \mathrm{c}$ ). In addition, terpenoids and fatty acid compounds were highlighted by a couple of signals captured by the NMR of the crude sample; their intensities were not as high as the flavonoids and phenolics. 


\begin{tabular}{|l|l|l|l|l|l|}
\hline Peak no & Retention time (min) & {$[\mathrm{M}-\mathrm{H}]-$} & Chemical formula & Delta (ppm) & Intensity \\
\hline 1 & 6.7 & 193.05 & $\mathrm{C}_{10} \mathrm{H}_{9} \mathrm{O}_{4}$ & -0.011 & E 6 \\
\hline 2 & 9.04 & 273.08 & $\mathrm{C}_{15} \mathrm{H}_{13} \mathrm{O}_{5}$ & 1.33 & E 7 \\
\hline 3 & 9.88 & 545.15 & $\mathrm{C}_{30} \mathrm{H}_{25} \mathrm{O}_{10}$ & 1.357 & E 7 \\
\hline 4 & 15.57 & 405.08 & $\mathrm{C}_{19} \mathrm{H}_{17} \mathrm{O}_{10}$ & 0.247 & E 7 \\
\hline 5 & 16.31 & 333.21 & $\mathrm{C}_{20} \mathrm{H}_{29} \mathrm{O}_{4}$ & 1.252 & E 7 \\
\hline 6 & 19.66 & 335.22 & $\mathrm{C}_{20} \mathrm{H}_{31} \mathrm{O}_{4}$ & 1.185 & E 7 \\
\hline 7 & 20.13 & 373.09 & $\mathrm{C}_{19} \mathrm{H}_{17} \mathrm{O}_{8}$ & 1.472 & E 7 \\
\hline 8 & 22.17 & 419.1 & $\mathrm{C}_{20} \mathrm{H}_{19} \mathrm{O}_{10}$ & 0.334 & E 8 \\
\hline 9 & 33.55 & 325.14 & $\mathrm{C}_{20} \mathrm{H}_{21} \mathrm{O}_{4}$ & 1.315 & E 7 \\
\hline 10 & 36.64 & 317.21 & $\mathrm{C}_{20} \mathrm{H}_{29} \mathrm{O}_{3}$ & 1.551 & E 7 \\
\hline
\end{tabular}

Table 1. Chemical profile of S-6 fraction by reverse-phase LC-MS.
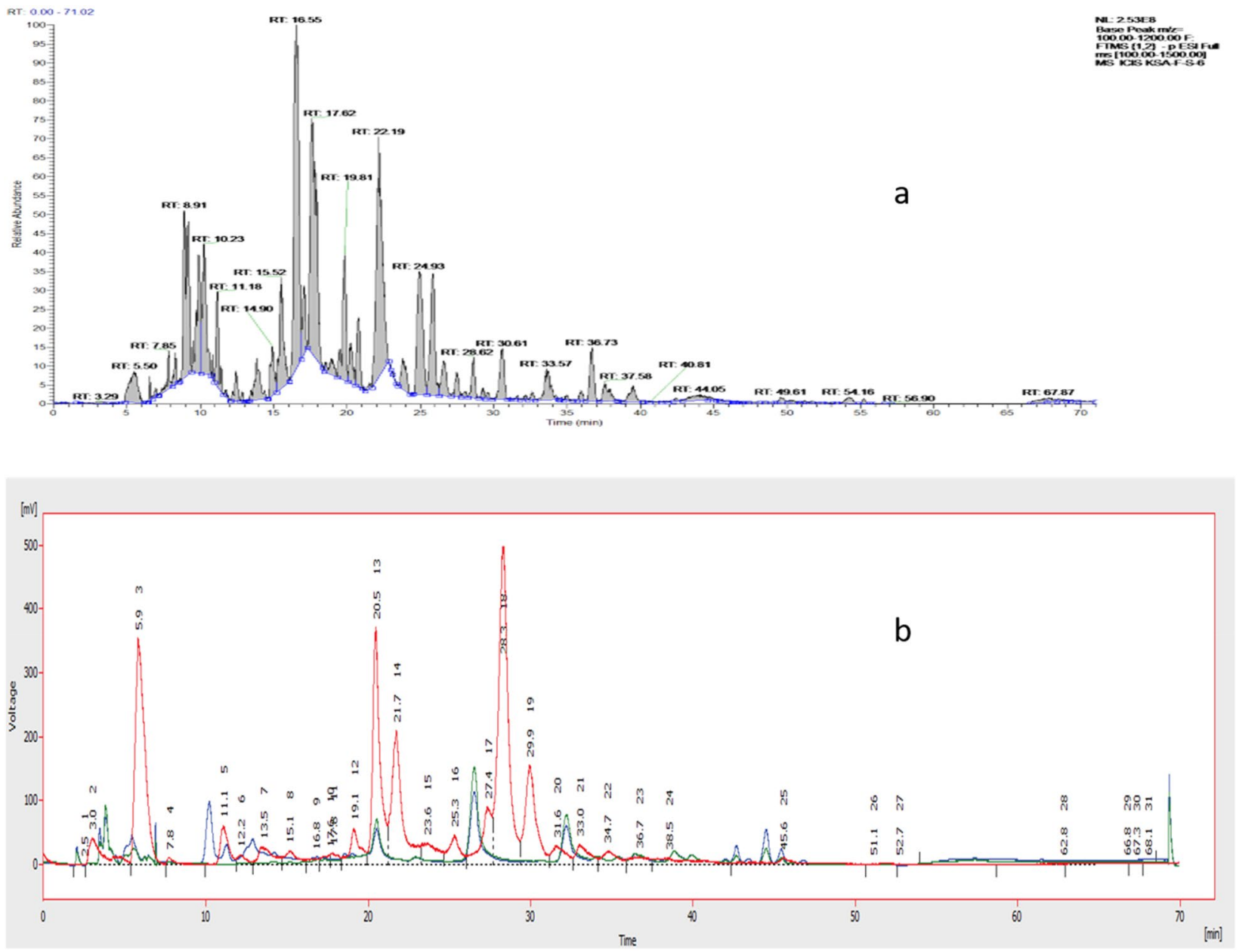

Figure 2. LC-MS Chromatogram of Saudi's crude propolis fraction (S-6) using (a) ESI; (b) ESD (compounds were mostly UV-absorbing, that could be flavonoids or phenolic with retention times of 40 and $60 \mathrm{~min}$ (red and blue spectra corresponds to flavanoids detected at 290 and $320 \mathrm{~nm}$ respectively); Terpenoids or fats or any other compounds without chromophores (green trace) were also detected but with low intensities.

Isolation and characterization of pure compounds. Column chromatography (CC) and size exclusion chromatography (SEC) were used to separate and purify propolis compounds. On CC, 28 fractions of the ethanol-based extract of propolis were obtained. The chromatographic characteristics were delineated via thin-layer chromatography using a suitable solvent system. The application of LC-MS and NMR permitted the identification of different components and allowed the combination of similar fractions. Similar fractions were combined to yield 10 pooled fractions. LC-MS and HPLC-UV-ELSD analysis revealed that the most abundant fraction, S-6, contained compounds with varied compositions, as shown in Table 1 and Fig. 2. The chromato- 
a

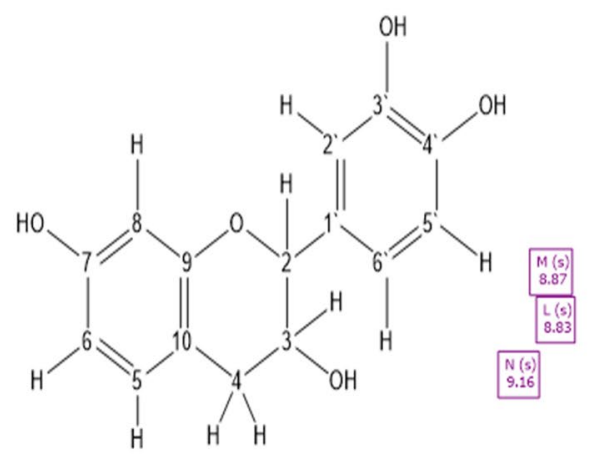

Figure 3. Characterization of S-6-7 as fisetinidol. (a) Structure of fisetinidol; (b) NMR spectrum of fisetinidol.

gram view of Saudi's fraction (S-6) on the ELSD showed that it contained mostly compounds with UV-absorbing activity, that could be flavonoids or phenols at retention times of 40 and 60 min (Fig. 2b). Terpenoids or fats, or any other compounds without chromophores were detected but at low intensities. Further, $475 \mathrm{mg}$ of the fraction (S-6) from the CC was subjected to SEC, yielding 23 sub-fractions (S-6-1 to S-6-23), which led to the acquisition of two pure compounds (S-6-7 and S-6-13).

Characterization of S-6-7 as fisetinidol. The complete characterization and structural elucidation of the S-6-7 fraction is depicted in Fig. 3. Analysis by LC-HRESI-MS gave a molecular ion at m/z 273.08 [M-H]-; a calculated mass of $\mathrm{C}_{15} \mathrm{H}_{13} \mathrm{O}_{5}=273.08$ (Fig. 3a), and the optical rotation had a value of $-5.9^{\circ}(c=0.085, \mathrm{MeOH})$. Its ${ }^{1} \mathrm{H}$ NMR spectrum showed two sets of aromatic ABX spin systems. The first set was at $\delta_{\mathrm{H}} \mathrm{ppm} 6.83$ (d, $J=8.23 \mathrm{~Hz}), 6.28(\mathrm{dd}, J=8.21,2.41)$, and $6.18(\mathrm{~d}, J=2.34)$. The second set of aromatic ABX protons was at 6.72 $(\mathrm{d}, J=2.01), 6.69(\mathrm{~d}, J=8.06)$, and $6.60(\mathrm{dd}, J=8.13,2.04)$. It also showed two oxymethine protons at 4.58 (d, $J=7.17)$ and $3.86(\mathrm{~m})$. There were also two methylene protons at $2.75(\mathrm{dd}, J=15.65,4.98)$ and $2.59(\mathrm{dd}, J=15.60$, 8.05). Finally, there three phenolic protons at $9.16(\mathrm{~s}), 8.87(\mathrm{~s})$, and $8.83(\mathrm{~s})$. The ${ }^{13} \mathrm{C}$ spectrum showed 15 signals consisting of six aromatic $\mathrm{CH}$ carbons and two oxymethine carbons at $\delta_{\mathrm{C}} \mathrm{ppm} 81.65$ and 66.79 . The rest of the carbon signals were for a methylene carbon at 32.71, four phenolic carbon atoms, and two aromatic quaternary carbons at 111.52 and $131.02 \mathrm{ppm}$. The absence of a hydrogen-bonded $-\mathrm{OH}$ proton around $12-13 \mathrm{ppm}$ and a carbonyl signal between 170 and $220 \mathrm{ppm}$ indicates the compound is not a flavone but a flavan derivative. This was confirmed from its 2D NMR spectrum as long-range HMBC correlations from H-2 to C-9, C-12, C-16, C-4, C-11, and C-3 were identified, while correlations from $\mathrm{H}-4$ to C-10, C-5, and C-9 were identified. The 7-OH gave correlations to C-6, C-7, and C-8. Other correlations from the HMQC and COSY confirmed the structure of the compound and the carbon and proton chemical shifts (Supplementary, Fig. S1a-d). The chemical structures of the main compounds identified are shown in Fig. 3a. This compound was identified as fisetinidol.

Characterization of S-6-13 as ferulic acid. CC and then SEC was performed to isolate S-6-13 from the ethanol it was extracted in.

Analysis by LC-HRESI-MS yielded a molecular ion at m/z $193.05[\mathrm{M}-\mathrm{H}]-$; a calculated mass of $\mathrm{C}_{10} \mathrm{H}_{9} \mathrm{O}_{4}=273.08$ (Fig. 4a). Figure $4 \mathrm{~b}$ depicts the ${ }^{1} \mathrm{H}-\mathrm{NMR}$ exhibiting two doublets at $\delta_{\mathrm{H}} 6.21(1 \mathrm{H}, \mathrm{d}, J=15.90$, $\mathrm{H}-8)$ and $7.48 \mathrm{ppm}(1 \mathrm{H}, \mathrm{d}, J=15.89, \mathrm{H}-7)$. Three aromatic proton signals at $7.32(1 \mathrm{H}, \mathrm{dd}, J=8.48,2.19, \mathrm{H}-6), 7.01$ $(1 \mathrm{H}, \mathrm{d}, J=8.47, \mathrm{H}-5)$, and $7.72(1 \mathrm{H}, \mathrm{d}, J=2.17, \mathrm{H}-2)$. It also showed a methoxy signal at $3.79\left(3 \mathrm{H}, \mathrm{s}, 5-\mathrm{OCH}_{3}\right)$. The ${ }^{13} \mathrm{C}-\mathrm{NMR}$ spectrum showed a deshielded signal at $\delta_{\mathrm{C}} 168.28 \mathrm{ppm}$ for a carboxylic acid carbonyl group (C-9), two olefinic $\mathrm{CH}$ at $116.86,144.36$, three aromatic $\mathrm{CH}$ at $112.92,119.9$, and 125.11 , two oxygenated aromatic carbons at 143.29 and 153.26 , a quaternary carbon at 126.72 , and a methoxy carbon at $56.16 \mathrm{ppm}$. This was confirmed from its 2D NMR spectrum as long-range $\mathrm{HMBC}$ correlations from $\mathrm{H}-2$ identified as C-4, C-6, and C-7, while correlations from H-5 identified as C-1 and C-3. Also, the correlations from H-6 were identified as C-2, C-4, and C-7, while the correlations from H-7 were identified as C-2, C-6, and C-9. HMBC correlations from H-8 were identified as C-1 and C-9. Other correlations from HMQC and COSY confirmed the compound's structure and the carbon and proton chemical shifts (Supplementary, Fig. S2a,b). The compound was identified as ferulic acid. 


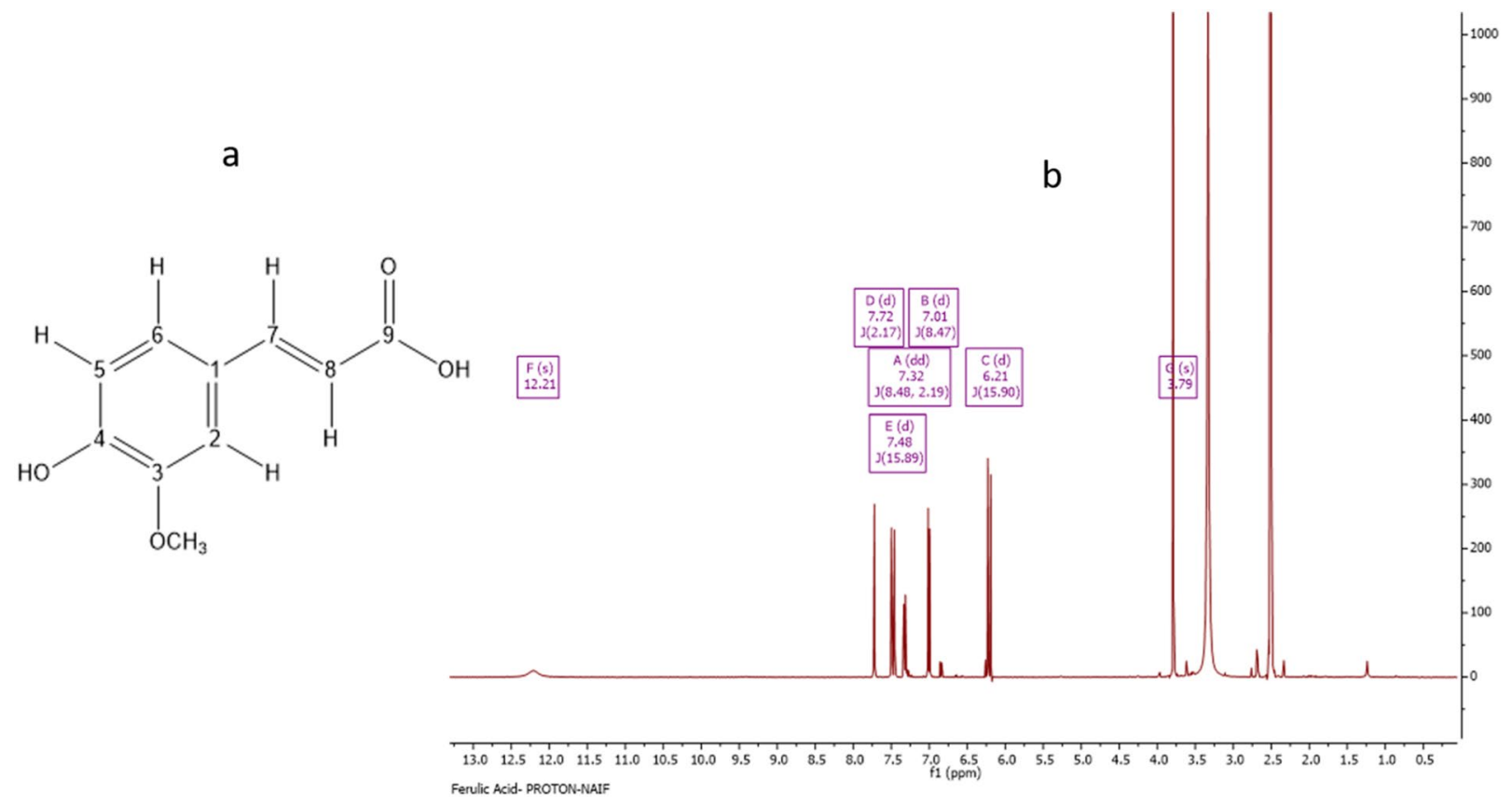

Figure 4. Characterization of S-6-13 as ferulic acid. (a) Structure of ferulic acid; (b) ${ }^{1} \mathrm{H}$ NMR spectrum (400 MHz) of ferulic acid (S-6-13).

\begin{tabular}{|l|l|l|}
\hline Sample code & Mean $(\mu \mathrm{g} / \mathrm{ml})$ & SD \\
\hline Saudi crude & 4.6 & 0.21 \\
\hline S-6 fraction & 2.4 & 0.24 \\
\hline Fisetinidol & 14.7 & 0.27 \\
\hline Ferulic acid & 39.9 & 1.19 \\
\hline Pentamidine $(\mu \mathrm{M})$ & 0.0030 & 0.0007 \\
\hline Diminazen $(\mu \mathrm{M})$ & 0.0313 & 0.0065 \\
\hline
\end{tabular}

Table 2. Drug Sensitivity assay of Saudi propolis sample and its fractions on T. brucei S427 WT.

\begin{tabular}{|l|l|l|l|}
\hline Sample code & $\mathbf{I C}_{50}$ mean $(\mu \mathrm{g} / \mathrm{ml})$ & SD & \%RSD \\
\hline Saudi crude & 129.1 & 6.85 & 5.31 \\
\hline S-6 fraction & 58.7 & 2.98 & 5.08 \\
\hline Fisetinidol & 256.9 & 30.19 & 11.75 \\
\hline Ferulic acid & 87.7 & 5.74 & 6.54 \\
\hline Pentamidine $(\mu \mathrm{M})$ & 13.3167 & 1.0148 & 7.6202 \\
\hline Diminazen $(\mu \mathrm{M})$ & 29.5767 & 2.1704 & 7.3381 \\
\hline
\end{tabular}

Table 3. Cytotoxicity assay of Saudi propolis sample and its fractions on U937 cells.

Biological evaluation of Saudi propolis sample against trypanosomes ( $T$. brucei 5427 strain). Crude, fractions, and pure compounds (fisetinidol and ferulic acid) extracted from Saudi propolis samples were tested against T. brucei. Pentamidine and Diminazen were used as drug controls with a minimum inhibitory concentration (MIC) score of 0.0030 and $0.0313 \mu \mathrm{g} / \mathrm{ml}$, respectively, as shown in Table 2. The S- 6 fraction demonstrated the highest anti-trypanosomal activity at $2.4 \mu \mathrm{g} / \mathrm{ml} \mathrm{MIC,} \mathrm{followed} \mathrm{by} \mathrm{Saudi} \mathrm{crude} \mathrm{with} 4.6 \mu \mathrm{g} /$ $\mathrm{ml} \mathrm{MIC,} \mathrm{where} \mathrm{fisetinidol} \mathrm{and} \mathrm{ferulic} \mathrm{acid} \mathrm{had} \mathrm{MICs} \mathrm{of} 14.7$ and $39.9 \mu \mathrm{g} / \mathrm{ml}$, respectively.

Anticancer effect of Saudi propolis. The cytotoxicity assay of the Saudi propolis sample and its fractions on U937 cells is shown in Table 3. 
The S- 6 fractions exhibited the highest cytotoxic activity against $\mathrm{U} 937$ cells with an $\mathrm{IC}_{50}$ of $58.7 \mu \mathrm{g} / \mathrm{ml}$ followed by ferulic acid with an $\mathrm{IC}_{50}$ of $87.7 \mu \mathrm{g} / \mathrm{ml}$, indicating that the cytotoxic effect of propolis might be attributed to the presence of ferulic acid.

\section{Discussion}

The present study demonstrated the anti-trypanosomal and anticancer properties of various propolis extracts crude and pure fractions, and the highest activity was found in the S- 6 fractions. The chemical profiling by GC-MS and ${ }^{1} \mathrm{H}$ NMR spectra demonstrated flavonoids and phenols in propolis extracts. All crude extracts, fractions, and isolated compounds (ferulic acid and fisetinidol) tested against Trypanosoma brucei (S427 WT) and for cytotoxicity against U937 human leukemia cells yielded satisfactory results. Among the samples tested, the highest antiparasitic and anticancer effect was observed in S-6 fractions due to the combined effect of ferulic acid, fisetinidol, and other various compounds.

The NMR spectral data (Fig. 3b) from the S-6-7 fraction was in agreement with previous reports ${ }^{25}$. The compound identified was fisetinidol, indicating that this compound is typical of Saudi propolis. Similarly, the S-6-13 fraction was identified as ferulic acid, and its NMR spectral data were in agreement with earlier findings ${ }^{26,27}$. The compounds detected are known constituents of propolis like ferulic acid. Yet, the presence of fesitinidol is comparatively rare. Propolis has been reported to contain over 300 compounds, but not all compounds are related to its biological effects. Standardization of propolis samples from different geographical areas with different biological effects has not been done. The occurrence of ferulic acid with the elemental composition of $\mathrm{C}_{10} \mathrm{H}_{9} \mathrm{O}_{4}$ in the propolis extract in the current study is consistent with findings from El-Mawla and Osman ${ }^{28}$. Several studies have reported the potential biological effects of these compounds against bacteria, cancer ${ }^{26-29}$, and leishmaniasis ${ }^{30}$ from different geographical regions. Reports on the biological activity of propolis are inconsistent, and little is known about the biological activities of Saudi propolis.

Trypanosoma brucei is a branching, flagellated protozoan parasite that causes sleeping sickness in humans and nagana in cattle in sub-Saharan Africa, where it can be devastating ${ }^{31}$. The current WHO estimate indicates that about 30,000 people are infected per year, and over 70 million people are at risk of infection ${ }^{32}$. Livestock in the Middle east is at higher risk of infection and heavy loss of cattle. Given the severity, the anti-trypanosomal property of the propolis was investigated. The observed anti-trypanosomal activity (Table 2) was in line with Khalil et al. ${ }^{33}$ and Alotaibi et al. ${ }^{34}$. Contrarily, Almutairi et al. found fisetinidol extracted from Saudi propolis to be inactive against trypanosomes and bacteria ${ }^{25}$. The main component of the S- 6 fraction exhibiting the highest antiparasitic effect identified in this study was fisetinidol. The observed decrease in the anti-trypanosomal activity of isolated compounds compared to the mixed fraction is in line with reports of Omar et al. ${ }^{35}$.

Chemotherapy is one of the major therapeutic approaches for treating benign and metastasized cancer; however it has some limitations. Hence, it is extremely important to design new, natural, and efficient drugs. Propolis has been shown to possess beneficial activities for human health since ancient times. Importantly, propolis was observed to play a key role in tumor regulation via its cytotoxic effects. Among the three tested samples S-6-7, ferulic acid, and fisetinidol, the S-6-7 fraction had the highest cytotoxicity while fisetinidol had the least. Between the two pure compounds, the cytotoxic activity of ferulic acid was much more pronounced. Thus, the cytotoxic activity of S-6-7 could be attributed to the presence of ferulic acid. Based on the above observations, ferulic acid was considered to enhance the cytotoxic property of the S-6-7 fraction. The decrease in the isolated fraction's anticancer activity compared to the mixed S- 6 fraction suggests a synergistic anticancer effect between the compounds. Nevertheless, there was significant anticancer property demonstrated by propolis. The cytotoxicity against cancer cells was in accordance with previous reports ${ }^{35-37}$.

As previously stated, the isolated compounds demonstrating lower activity than the mixed fraction or the crude extract could be reasoned as follows; retention of the active compound in the column; instability of the active compound in the conditions used in the isolation process; the distribution of the majority of active constituents over different fractions; or synergistic interaction between several compounds may be the source of the extract effects ${ }^{38}$. In line with current report, many studies have revealed that the observed effects might be the result of synergistic action of its complex constituents and propolis exhibiting higher activity than isolated compounds ${ }^{39,40}$. Based on the current investigation's data, Saudi propolis emerged to possess biological activity as a promising antiparasitic and anticancer agent.

\section{Methods}

Collection and preparation of the propolis sample. The Saudi propolis sample was collected from the Rijal Alma'a village, Asir region (N 2015840.65, E 211634.87), South-west of Saudi Arabia during summer. The samples were stored at room temperature, away from light and humidity, until further analysis.

Processing and ethanolic extraction of Propolis samples. Raw propolis was macroscopically screened to remove impurities (e.g., pollen, wood, and dead bees) prior to extraction. A mortar and pestle were used to fragment the samples of propolis. For extraction, $5 \mathrm{ml}$ of ethanol was added to $50 \mathrm{mg}$ of propolis sample and sonicated for $180 \mathrm{~min}$, and reextracted thrice. A syringe filter (Acrodisc $0.45 \mu \mathrm{m}$ ) was used to filter the samples, and a nitrogen flow was used for drying the filtered solution. To obtain pure components, further fractionation, and purification of raw propolis was achieved by CC and SEC. An appropriate quantity of absolute ethanol $(100 \mathrm{ml} / \mathrm{g})$ was added to raw propolis and sonicated for an hour to obtain ethanol-based extract for fractionation. An appropriate quantity of ethanol was subsequently used to filter and re-extract two times, with subsequent filtering every time. After the extracts were merged, a rotary evaporator was used to evaporate and dry the solvent, followed by weighing. An extraction yield of $12.8869 \mathrm{~g}$ was obtained. A small quantity ( $1 \mathrm{ml})$ of ethyl acetate was used to re-dissolve the residue $(2 \mathrm{mg})$ completely, followed by sonication to stimulate the dis- 
solution of the residue. The extracted solution was poured into empty weighed vials and labeled. Crude propolis samples and purified fractions were analyzed by LC-MS, HPLC in association with a range of detectors, including ELSD, UV, and high resolution mass spectrometry, as well as NMR spectroscopy.

Isolation and characterization of pure compounds. CC and SEC. Isolation and purification of compounds from the crude extract were achieved by employing CC and SEC ${ }^{41,42}$. Around $6.25 \mathrm{~g}$ of the ethanol-based extract of Saudi propolis was subjected to CC and gradient elution with solvents of different polarities. Silica gel 60 with a mesh size of $200-425 \mu \mathrm{m}$ was used. A rotatory evaporator was used to collect and concentrate the fractions, which were then aggregated via HPLC-UV-ELSD analysis based on similar chemical profiles. For SEC, Sephadex LH 20 was used for column packing, and elution was performed in an isocratic manner with methanol.

LC-MS. LC/MS was carried out using a Dionex 3000 UHPLC pump coupled to an Exactive (Orbitrap) Mass spectrometer, Thermo Fisher Scientific (Bremen, Germany). Crude samples and purified compounds were prepared at $1 \mathrm{mg} / \mathrm{ml}$ in methanol prior to LC-MS. A reverse-phase $5 \mu \mathrm{m} \mathrm{C18} \mathrm{column}(4.6 \times 150 \mathrm{~mm})$ (Hypersil, Thermo) was used, and the elution was carried out using a gradient at a flow rate of $0.3 \mathrm{ml} / \mathrm{min}$, with $0.1 \% \mathrm{v} / \mathrm{v}$ formic acid in water and $0.1 \% \mathrm{v} / \mathrm{v}$ formic acid in acetonitrile (the A and B solvents) making up the mobile phase. The ESI interface in negative ionization permitted identification of $[\mathrm{M}-\mathrm{H}]$-. The spray voltage for the capillary and cone were $-4.0 \mathrm{kV}$ and $35 \mathrm{~V}$, respectively. The flow rate of the sheath gas and auxiliary gas were 50 and 15 arbitrary units, respectively. The ion transfer capillary had a temperature of $275{ }^{\circ} \mathrm{C}$, and $\mathrm{m} / \mathrm{z}$ between 100 and 1500 provided the full scan data ${ }^{43}$. The sample data were acquired and processed with Xcalibur software (Thermo Fisher Corporation, Hemel Hempstead, UK).

HPLC-UV-ELSD. A $1 \mathrm{mg} / \mathrm{ml}$ solution was produced for every sample dried under nitrogen in $1 \mathrm{ml}$ of the mobile phase LC gradient's initial composition. A reverse-phase $5 \mu \mathrm{m}$ C18 column $(4.6 \times 150 \mathrm{~mm})$ (Hypersil, Thermo) was employed for separation purposes, with water and acetonitrile (the A and B solvents) in the mobile phase. An Agilent 1100 system (Agilent Technologies, Germany) consisting of a quaternary pump, a diode array UV detector (set to monitor 290 and $320 \mathrm{~nm}$ wavelengths), and an ELSD (SEDEX75 SEDERE, France) constituted the used HPLC-UV-ELSD equipment. Data were collected and processed using Clarity software (Data Apex $)^{44}$.

Structural elucidation by nuclear magnetic resonance spectroscopy (NMR). The ${ }^{1} \mathrm{H},{ }^{13} \mathrm{C}$, and $2 \mathrm{D}{ }^{1} \mathrm{H},{ }^{1} \mathrm{H}$-COSY, ${ }^{13} \mathrm{C}-1 \mathrm{H}$ HSQC, and HMBC NMR spectra were obtained using a JEOL-LA 400 FT-NMR spectrometer with tetramethylsilane (TMS) as an internal standard ${ }^{45,46}$. Based on the solubility of the compounds, preparation of the sample solutions involved the use of deuterated solvents like $\mathrm{CDCl} 3$ and DMSO-d6 that have residual proton shifts and carbon shifts. Around $500-600 \mu \mathrm{l}$ of a suitable solvent was used to dissolve $10 \mathrm{mg}$ of every sample, which was then poured into a typical $5 \times 178 \mathrm{~mm}$ NMR tube to a depth of around $4 \mathrm{~cm}$. MestReNova software 8.1.2 (Mestrelab Research, A Coruña, Spain) was used to process the NMR spectroscopic data, and the structures of the compounds were illustrated using ChemBioDraw Ultra, Version 14 (PerkinElmer, Yokohama, Japan).

Cell culture and medium preparation. The U937 cells (a human monocytes cell line), were cultured in the RPMI 1640 medium $(500 \mathrm{ml})$, which was supplemented with $1 \%$ penicillin and streptomycin $(\mathrm{v} / \mathrm{v}), 1 \%$ L-glutamine (v/v), and 5\% FCS (v/v). Cells were sub-cultured every $2-4$ days and maintained at $37^{\circ} \mathrm{C}$ in $5 \% \mathrm{CO}_{2}$.

Cell viability assay. The U937 cells were seeded at $1 \times 10^{5}$ cells $/ \mathrm{ml}$ in 96 -well plates. The cells were counted manually using a haemocytometer under a microscope. The cells were added and the plate incubated for $24 \mathrm{~h}$ at $37^{\circ} \mathrm{C}$ in $5 \% \mathrm{CO}_{2}$. The samples (the crude, fractions, and purified compounds) were prepared at 8 different concentrations in another 96 well plate to prevent disturbing the cells during mixing since U937 cells do not adhere. The highest concentration started from $200 \mu \mathrm{g} / \mathrm{ml}$ and a serial 1:2 dilution was carried out until the concentration was $1.56 \mu \mathrm{g} / \mathrm{ml}(\mathrm{n}=3)$. The samples were then transferred $(100 \mu \mathrm{l})$ to the cultured cells using a multichannel pipette and placed in the incubator for $24 \mathrm{~h} .10 \%(\mathrm{v} / \mathrm{v})$ DMSO was added to serve as a positive control (to kill the cells completely). The cells in medium alone were used as a negative control and $0.5 \%(\mathrm{v} / \mathrm{v}) \mathrm{DMSO}$ (the solvent concentration in the samples) was tested as well. The plate was then incubated at $37^{\circ} \mathrm{C}$ in $5 \% \mathrm{CO}_{2}$ for $24 \mathrm{~h}$. After incubation, the resazurin indicator (Alamar blue) was added at a final concentration of $10 \%$ and incubated for a further $24 \mathrm{~h}$. Fluorescence was read using a Wallac Victor 2 microplate reader ( $\lambda$ Ex/EM: 560/590 nm). Cell viability was then calculated for each well as the percentage of fluorescence in the test samples relative to the values of the negative controls. The resulting data were analyzed with GraphPad Prism 5 to obtain dose-response curves for each sample and their corresponding $\mathrm{IC}_{50}$ values.

Anti-trypanosomal assay. Crude extracts, fractions, and isolated compounds were tested against the bloodstream form of wild-type Trypanosoma brucei (S427) in vitro. Trypanosoma brucei, Lister 427 were cultured as previously described ${ }^{47}$. The anti-trypanosomal tests were carried out using an Alamar blue assay ${ }^{48}$. This assay is based on viable cells metabolizing the blue resazurin dye to resorufin, which is pink and fluorescent. It was performed using stock solutions of the samples prepared with a $20 \mathrm{mg} / \mathrm{ml}$ concentration in $100 \%$ DMSO with subsequent dilution of DMSO concentration to $0.1 \%$. The assays were performed using (1:1) serial dilution of test compounds in Hirumi's Modified Iscove's medium 9 (HMI-9), where $100 \mu \mathrm{l}$ of each compound or frac- 
tion was doubling diluted over one row in the 96-well plate, (starting from $200 \mu \mathrm{g} / \mathrm{ml}$ as the top concentration until $0.19 \mu \mathrm{g} / \mathrm{ml}$ ) ensuring an optimally defined $50 \%$ Effective Concentration $\left(\mathrm{EC}_{50}\right)$ after plotting the reading to a sigmoid curve with a variable slope using GraphPad Prism software. A $100 \mu \mathrm{l}$ of trypanosome suspension was eventually added to each well plate at a seeding density of $2 \times 10^{5}$ cells followed by an incubation period of $48 \mathrm{~h}$ at $37^{\circ} \mathrm{C}$ in a $5 \% \mathrm{CO}_{2}$ humidified incubator. Before adding the resazurin dye and further incubation for $24 \mathrm{~h}$ under the same conditions, fluorescence was determined in a FLUOstar Optima (BMG Labtech) at wavelengths of $544 \mathrm{~nm}$ and $620 \mathrm{~nm}$ for excitation and emission, respectively.

Received: 1 November 2020; Accepted: 12 February 2021

Published online: 08 March 2021

\section{References}

1. Bankova, V., Popova, M. \& Trusheva, B. The phytochemistry of the honeybee. Phytochemistry 155, 1-11 (2018).

2. Jerz, G. et al. Preparative mass-spectrometry profiling of bioactive metabolites in Saudi-Arabian propolis fractionated by highspeed countercurrent chromatography and off-line atmospheric pressure chemical ionization mass-spectrometry injection. J. Chromatogr. A 1347, 17-29 (2014).

3. Alqarni, A. S., Hannan, M. A., Owayss, A. A. \& Engel, M. S. The indigenous honey bees of Saudi Arabia (Hymenoptera, Apidae, Apis mellifera jemenitica Ruttner): Their natural history and role in beekeeping. ZooKeys 83, 83-98 (2011).

4. Wagh, V. D. Propolis: A wonder bees product and its pharmacological potentials. Adv. Pharmacol. Sci. 2013, 1-11 (2013).

5. Nicodemo, D., De Jong, D., Couto, R. H. \& Malheiros, E. B. Honey bee lines selected for high propolis production also have superior hygienic behavior and increased honey and pollen stores. Genet. Mol. Res. 12, 6931-6938 (2013).

6. Popova, M. P., Graikou, K., Chinou, I. \& Bankova, V. S. GC-MS profiling of diterpene compounds in Mediterranean propolis from Greece. J. Agric. Food Chem. 58, 3167-3176 (2010).

7. Huang, S. et al. Recent advances in the chemical composition of propolis. Molecules 19, 19610-19632 (2014).

8. Fernandes-Silva, C. C., Freitas, J. C., Salatino, A. \& Salatino, M. L. Cytotoxic activity of six samples of Brazilian propolis on sea urchin (Lytechinus variegatus) eggs. Evid. Based Complement. Alternat. Med. eCAM 2013, 619361 (2013).

9. Marcucci, M. C. Propolis: Chemical composition, biological properties and therapeutic activity. Apidologie 26, 83-99 (1995).

10. Siripatrawan, U., Vitchayakitti, W. \& Sanguandeekul, R. Antioxidant and antimicrobial properties of Thai propolis extracted using ethanol aqueous solution. Int. J. Food Sci. Technol. 48, 22-27 (2013).

11. Bankova, V. Chemical diversity of propolis makes it a valuable source of new biologically active compounds. J. Api Prod. Api Med. Sci. 1, 2328 (2009).

12. Shubharani, R., Sivaram, V. \& Kishore, B. In-vitro cytotoxicity of Indian bee propolis on cancer cell lines. Int. J. Pharm. Biol. Sci. 5, 698-706 (2014).

13. Coggshall, W. L. \& Morse, R. A. Beeswax: Production, harvesting, processing and products. Beeswax Prod. Harvesting Process. Prod. (1984)

14. Krell, R. Value-Added Products from Beekeeping, Food \& Agriculture Org (1996).

15. Nedji, N. \& Loucif-Ayad, W. Antimicrobial activity of Algerian propolis in foodborne pathogens and its quantitative chemical composition. Asian Pac. J. Trop. Dis. 4, 433-437 (2014).

16. Campos, J. F. et al. Antimicrobial, antioxidant and cytotoxic activities of propolis from Melipona orbignyi (Hymenoptera, Apidae). Food Chem. Toxicol. 65, 374-380 (2014).

17. Paulino, N. et al. Anti-inflammatory effects of a bioavailable compound, Artepillin C, in Brazilian propolis. Eur. J. Pharmacol. 587, 296-301 (2008).

18. Franchi, G. C. et al. Comparison of effects of the ethanolic extracts of Brazilian propolis on human leukemic cells as assessed with the MTT assay. Evid. Based Complement. Altern. Med. 2012, 918956 (2012).

19. Utispan, K., Chitkul, B. \& Koontongkaew, S. Cytotoxic activity of propolis extracts from the stingless bee Trigona Sirindhornae against primary and metastatic head and neck cancer cell lines. Asian Pac. J. Cancer Prev. 18, 1051-1055 (2017).

20. Dantas, A. P., Olivieri, B. P., Gomes, F. H. M. \& De Castro, S. L. Treatment of Trypanosoma cruzi-infected mice with propolis promotes changes in the immune response. J. Ethnopharmacol. 103, 187-193 (2006).

21. Fischer, G. et al. Immunomodulation produced by a green propolis extract on humoral and cellular responses of mice immunized with SuHV-1. Vaccine 25, 1250-1256 (2007).

22. Cheung, K. W. et al. Brazilian green propolis and its constituent, Artepillin C inhibits allogeneic activated human CD4 T cells expansion and activation. J. Ethnogr. Pharmacol. 138, 463-471 (2011).

23. Paviani, L. C. et al. Supercritical CO 2 extraction of raw propolis and its dry ethanolic extract. Braz. J. Chem. Eng. 29, 243-251 (2012).

24. Cao, J. et al. Ultrasound-assisted ionic liquid-based micellar extraction combined with microcrystalline cellulose as sorbent in dispersive microextraction for the determination of phenolic compounds in propolis. Anal. Chim. Acta 963, 24-32 (2017).

25. Almutairi, S. et al. Isolation of diterpenes and flavonoids from a new type of propolis from Saudi Arabia. Phytochem. Lett. 10, $160-163(2014)$.

26. Yoshioka, T., Inokuchi, T., Fujioka, S. \& Kimura, Y. Phenolic compounds and flavonoids as plant growth regulators from fruit and leaf of Vitex rotundifolia. Z. Nat. C 59, 509-514 (2004).

27. Liao, C. R. et al. Studies on cytotoxic constituents from the leaves of Elaeagnus oldhamii Maxim. in non-small cell lung cancer A549 cells. Molecules 19, 9515-9534 (2014).

28. El-Mawla, A. M. A. \& Osman, H. E. H. HPLC analysis and role of the Saudi Arabian propolis in improving the pathological changes of kidney treated with monosodium glutamate. J. Complement. Drug Discov. 1, 119-127 (2011).

29. Chang, S. W. et al. Phytochemical constituents of Bistorta manshuriensis. Nat. Prod. Sci. 15, 234-240 (2009).

30. Tasdemir, D. et al. Antitrypanosomal and antileishmanial activities of flavonoids and their analogues: In vitro, in vivo, structureactivity relationship, and quantitative structure-activity relationship studies. Antimicrob. Agents Chemother. 50, 1352-1364 (2006).

31. Zhou, Q., Hu, H. \& Li, Z. New insights into the molecular mechanisms of mitosis and cytokinesis in trypanosomes. Int. Rev. Cell Mol. Biol. 308, 127-166 (2014).

32. WHO (Report). Human African Trypanosomiasis (2020). https://www.who.int/news-room/fact-sheets/detail/trypanosomiasis -human-african-(sleeping-sickness) (Accessed 3 October 2020).

33. Khalil, M. L. Biological activity of bee propolis in health and disease. Asian Pac. J. Cancer Prev. 7, 22-31 (2006).

34. Alotaibi, A. et al. European propolis is highly active against trypanosomatids including Crithidia fasciculata. Sci. Rep. 9, 11364 (2019).

35. Omar, R. et al. The chemical characterization of Nigerian propolis samples and their activity against Trypanosoma brucei. Sci. Rep. 7, 923 (2017). 
36. Elnakady, Y. A. et al. Characteristics, chemical compositions and biological activities of propolis from Al-Bahah, Saudi Arabia. Sci. Rep. 7, 41453 (2017).

37. Ishida, Y. et al. Anticancer Activity in Honeybee Propolis: functional Insights to the Role of caffeic acid phenethyl ester and its Complex With $\gamma$-cyclodextrin. Integr. Cancer Ther. 17, 867-873 (2018).

38. Sarker, S. D. \& Nahar, L. Follow-up of natural products isolation. In Natural Products Isolation 3rd edn (eds Sarker, S. D. \& Nahar, L.) 473-514 (Humana Press/Springer, 2012).

39. Sforcin, J. M., Orsi, R. O. \& Bankova, V. Effect of propolis, some isolated compounds and its source plant on antibody production. J. Ethnopharmacol. 98, 301-305 (2005).

40. Bueno-Silva, B. et al. Anti-inflammatory and antimicrobial evaluation of neovestitol and vestitol isolated from Brazilian red propolis. J. Agric. Food Chem. 61, 4546-4550 (2013).

41. Heftmann, E. Chromatography: Fundamentals and Applications of Chromatography and Related Differential Migration Methods-Part B: Applications (Elsevier, 2004).

42. Salituro, G. M. \& Dufresne, C. Isolation by low-pressure column chromatography. In Natural Products Isolation (ed. Cannell, R. J. P.) (Springer, 1998).

43. Watson, J. T. \& Sparkman, O. D. Introduction to Mass Spectrometry: Instrumentation, Applications, and Strategies for Data Interpretation 4 th edn. (Wiley, 2007).

44. Young, C. S. \& Dolan, J. W. Success with evaporative light-scattering detection. LCGC N. Am. 21, 120-128 (2003).

45. Stoyanova, R. \& Brown, T. R. NMR spectral quantitation by principal component analysis. NMR Biomed. 14, 271-277 (2001).

46. Claridge, T. D. High-Resolution NMR Techniques in Organic Chemistry 3rd edn. (Elsevier, 2016).

47. Yang, H. et al. Antioxidant compounds from propolis collected in Anhui, China. Molecules 16, 3444-3455 (2011).

48. Raz, B., Iten, M., Grether-Buhler, Y., Kaminsky, R. \& Brun, R. The Alamar Blue1 assay to determine drug sensitivity of African trypanosomes (Tb rhodesiense and Tb gambiense) in vitro. Acta Trop. 68, 139-147 (1997).

\section{Acknowledgements}

This research project was supported by a grant from the "Research Center of the Female Scientific and Medical Colleges", Deanship of Scientific Research, King Saud University. The authors are also thankful to Research Support and Services Unit, King Saud University for technical support.

\section{Author contributions}

Conceptualisation, N.A. and D.W.; Data curation, H.T. and S.A.; Methodology, N.A., S.A. and F.A.; Supervision, D.W.; Writing-original draft, N.A.; Writing-review and editing, H.T., and S.A.

\section{Competing interests}

The authors declare no competing interests.

Additional information

Supplementary Information The online version contains supplementary material available at https://doi. org/10.1038/s41598-021-84717-5.

Correspondence and requests for materials should be addressed to N.A.

Reprints and permissions information is available at www.nature.com/reprints.

Publisher's note Springer Nature remains neutral with regard to jurisdictional claims in published maps and institutional affiliations.

(c) (i) Open Access This article is licensed under a Creative Commons Attribution 4.0 International cc) License, which permits use, sharing, adaptation, distribution and reproduction in any medium or format, as long as you give appropriate credit to the original author(s) and the source, provide a link to the Creative Commons licence, and indicate if changes were made. The images or other third party material in this article are included in the article's Creative Commons licence, unless indicated otherwise in a credit line to the material. If material is not included in the article's Creative Commons licence and your intended use is not permitted by statutory regulation or exceeds the permitted use, you will need to obtain permission directly from the copyright holder. To view a copy of this licence, visit http://creativecommons.org/licenses/by/4.0/.

(C) The Author(s) 2021 